
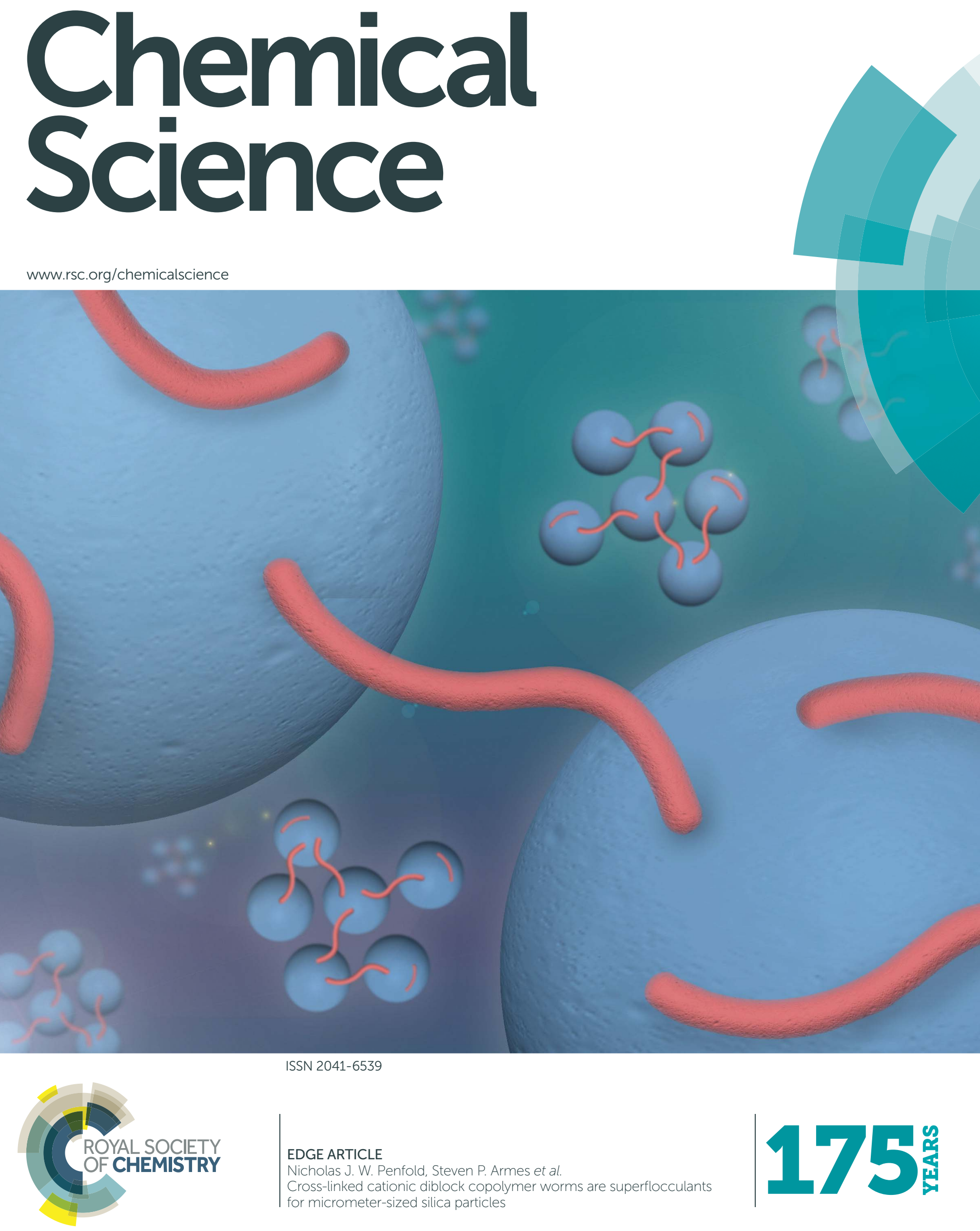


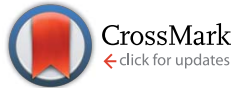

Cite this: Chem. Sci., 2016, 7, 6894

\title{
Cross-linked cationic diblock copolymer worms are superflocculants for micrometer-sized silica particles $\dagger$
}

\author{
Nicholas J. W. Penfold, ${ }^{\text {a }}$ Yin Ning, ${ }^{a}$ Pierre Verstraete, ${ }^{b}$ Johan Smets ${ }^{b}$ \\ and Steven P. Armes ${ }^{* a}$
}

A series of linear cationic diblock copolymer nanoparticles are prepared by polymerization-induced selfassembly (PISA) via reversible addition-fragmentation chain transfer (RAFT) aqueous dispersion polymerization of 2-hydroxypropyl methacrylate (HPMA) using a binary mixture of non-ionic and cationic macromolecular RAFT agents, namely poly(ethylene oxide) $\left(\mathrm{PEO}_{113}, M_{\mathrm{n}}=4400 \mathrm{~g} \mathrm{~mol}^{-1}\right.$; $\left.M_{\mathrm{w}} / M_{\mathrm{n}}=1.08\right)$ and poly([2-(methacryloyloxy)ethyl]trimethylammonium chloride) (PQDMA $\mathrm{A}_{125}$, $M_{\mathrm{n}}=31800 \mathrm{~g} \mathrm{~mol}^{-1}, M_{\mathrm{w}} / M_{\mathrm{n}}=1.19$ ). A detailed phase diagram was constructed to determine the maximum amount of PQDMA ${ }_{125}$ stabilizer block that could be incorporated while still allowing access to a pure worm copolymer morphology. Aqueous electrophoresis studies indicated that zeta potentials of +35 mV could be achieved for such cationic worms over a wide $\mathrm{pH}$ range. Core cross-linked worms were prepared via statistical copolymerization of glycidyl methacrylate (GlyMA) with HPMA using a slightly modified PISA formulation, followed by reacting the epoxy groups of the GlyMA residues located within the worm cores with 3-aminopropyl triethoxysilane (APTES), and concomitant hydrolysis/ condensation of the pendent silanol groups with the secondary alcohol on the HPMA residues. TEM and DLS studies confirmed that such core cross-linked cationic worms remained colloidally stable when challenged with either excess methanol or a cationic surfactant. These cross-linked cationic worms are shown to be much more effective bridging flocculants for $1.0 \mu \mathrm{m}$ silica particles at $\mathrm{pH} 9$ than the corresponding linear cationic worms (and also various commercial high molecular weight water-soluble polymers.). Laser diffraction studies indicated silica aggregates of around 25-28 $\mu \mathrm{m}$ diameter when using the former worms but only 3-5 $\mu \mathrm{m}$ diameter when employing the latter worms. Moreover, SEM studies confirmed that the cross-linked worms remained intact after their adsorption onto the silica particles, whereas the much more delicate linear worms underwent fragmentation under the same conditions. Similar results were obtained with $4 \mu \mathrm{m}$ silica particles.

Received 19th August 2016

Accepted 12th September 2016

DOI: $10.1039 / c 6 s c 03732 a$

www.rsc.org/chemicalscience

\section{Introduction}

The controlled aggregation of colloidal particles plays a vital role in many important industrial processes such as paper manufacture $^{\mathbf{1 , 2}}$ mineral separation ${ }^{3}$ and water purification..$^{4-6}$

\footnotetext{
${ }^{a}$ Department of Chemistry, University of Sheffield, Brook Hill, Sheffield, South Yorkshire,S3 7HF, UK. E-mail: njwpenfopld1@sheffield.ac.uk; s.p.armes@sheffield. ac.uk

${ }^{b}$ Procter \& Gamble, Eurocor NV/SA, Temselaan 100, 1853 Strombeek-Bever, Belgium $\dagger$ Electronic supplementary information (ESI) available: Macro-CTAs and the worm cross-linking chemistry; suggested mechanism for the break-up of linear worms; UV-visible spectroscopy data and assigned ${ }^{1} \mathrm{H}$ NMR spectrum for the $\mathrm{PEO}_{113}$ macro-CTA; THF and aqueous GPC data for $\mathrm{PEO}_{113}$ and $\mathrm{PQDMA}_{120}$ macro-CTAs; kinetic data for the aqueous solution polymerization of QDMA monomer; assigned ${ }^{1} \mathrm{H}$ NMR for PQDMA $\mathrm{A}_{125}$ macro-CTA; additional TEM images and further laser diffraction traces; DLS particle size distributions; tabulated data for linear and cross-linked cationic worms diluted at pH 9 using either water or methanol; full experimental section. See DOI: 10.1039/c6sc03732a
}

Historically, silica suspensions have been used as models to assess the flocculation efficiency of various high molecular weight water-soluble polymers. ${ }^{7,8}$ Typically, soluble cationic polyelectrolytes (or non-ionic polymers) ${ }^{\mathbf{9 - 1 3}}$ have been evaluated as flocculants for such anionic particles. This approach is wellestablished for nano-sized silica particles, since the length scales of the particles and the flocculant are comparable (see Scheme 1a). However, for micrometer-sized silica particles, this usually leads to steric stabilization rather than bridging flocculation (see Scheme 1b). This qualitatively different behavior is the result of the mismatch in length scales for the two components. However, as far as we are aware, polyelectrolytic block copolymer nanoparticles have not yet been evaluated as flocculants for relatively large silica particles. In particular, cylindrical or worm-like nanoparticles can be formed by various diblock copolymers for a relatively narrow range of compositions. ${ }^{\mathbf{1 4 - 2 5}}$ The highly anisotropic nature of such nanoparticles leads to a much longer effective length scale, which should enable 
(a)

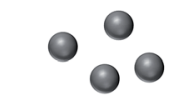

Ultrafine $10-30 \mathrm{~nm}$ anionic silica sols

(b)

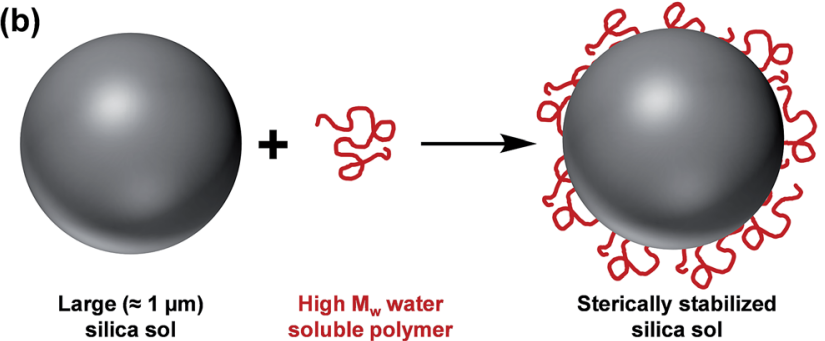

Scheme 1 (a) Flocculation of nanometer-sized silica sols and (b) steric stabilization of micrometer-sized silica sols on addition of a high molecular weight water-soluble polymer.

effective inter-particle bridging. More specifically, in the present study we hypothesized that cationic worms might act as efficient flocculants.

Over the last decade or so, various research groups have demonstrated the versatility of polymerization-induced selfassembly (PISA) for the design of bespoke functional AB diblock copolymer nanoparticles. ${ }^{26-46}$ Such PISA formulations are based on either dispersion or emulsion polymerization and can be conducted at relatively high copolymer concentrations (up to $50 \% \mathrm{w} / \mathrm{w}$ ) in either polar (e.g. water or lower alcohols) or nonpolar solvents (e.g. $n$-alkanes, mineral oil or $\operatorname{poly}(\alpha$-olefins $))^{47-53}$ Briefly, a macromolecular chain transfer agent (macro-CTA) is used as a soluble stabilizer 'A' block and self-assembly occurs in situ as the growing second 'B' block gradually becomes insoluble in the polymerization medium. Various nanoparticle morphologies can be accessed using this approach, including spheres, worms, unilamellar vesicles, oligolamellar vesicles, framboidal vesicles and platelet-like lamella sheets. ${ }^{54-57}$ In particular, the worm morphology has received much recent attention since it offers interesting applications such as sterilisable biocompatible hydrogels, ${ }^{57}$ viscosity modifiers, ${ }^{19,58} 3 \mathrm{D}$ cell culture media, ${ }^{59}$ efficient Pickering emulsifiers, ${ }^{60}$ a costeffective storage medium for stem cell transportation and the effective cryopreservation of red blood cells. ${ }^{61}$ Furthermore, certain diblock copolymer worms can undergo an order-order morphology transition on exposure to external stimuli such as $\mathrm{pH}$ or temperature. ${ }^{62-67}$ Several techniques have been developed for the preparation of cross-linked block copolymer nanoparticles. ${ }^{15,19,68-74}$ In situ core cross-linking of nanoparticles prepared by PISA can be achieved by either (i) addition of a divinyl comonomer during the latter stages of the polymerization $^{60,75}$ or (ii) the post-polymerization addition of a suitable cross-linking agent. ${ }^{76}$ The preparation of cross-linked spheres or vesicles is relatively straightforward. ${ }^{60,71,77,78}$ However, the preparation of cross-linked block copolymer worms is much more challenging. This is in part because of their tendency to form free-standing gels under the PISA synthesis conditions, which makes the post-polymerization addition of cross-linker reagents somewhat problematic. ${ }^{58}$ Moreover, addition of a divinyl comonomer can sometimes lead to (partial) loss of the desired worm copolymer morphology, because this occupies relatively narrow phase space. ${ }^{60}$ Nevertheless, Lovett and co-workers have recently reported the preparation of core crosslinked worms via statistical copolymerization of 2-hydroxypropyl methacrylate (HPMA) and glycidyl methacrylate (GlyMA) to form an epoxy-functional core-forming block. Post-polymerization addition of 3-aminopropyl triethoxysilane (APTES) leads to an epoxy-amine reaction within the worm cores, with concomitant siloxane hydrolysis and condensation with secondary hydroxyl groups located on neighboring HPMA residues leading to extensive cross-linking. ${ }^{76}$ Such non-ionic cross-linked worms remained colloidally stable in the presence of excess methanol (which is a good solvent for the core-forming block) or on addition of anionic surfactant.

Semsarilar and co-workers reported that using polyelectrolytic macro-CTAs in PISA formulations typically leads to purely spherical morphologies due to the strong lateral repulsion between the charged stabilizer chains. ${ }^{79,80}$ Even with the addition of salt to screen the unfavorable electrostatics, higher order morphologies such as worms and vesicles could not be observed. However, judicious dilution of the polyelectrolytic stabilizer blocks via addition of a non-ionic macro-CTA during the PISA synthesis allowed access to both worms and vesicles. ${ }^{80}$ Unfortunately, such linear anionic or cationic worms rapidly dissociate to form individual copolymer chains in the presence of surfactant. Moreover, negative zeta potentials were observed above $\mathrm{pH} 7$ as a result of the relatively short cationic poly([2-(methacryloyloxy)ethyl]trimethylammonium chloride) $\left(\mathrm{PQDMA}_{32}\right)$ macro-CTA utilized, although the use of a carboxylic acid-based RAFT CTA and azo initiator in this PISA formulation may also have contributed to this problem.

Herein we report the synthesis of both linear and crosslinked cationic block copolymer worms using a binary macroCTA approach via RAFT-mediated PISA. The two macro-CTAs employed in this approach are poly(ethylene oxide) (PEO) and PQDMA. The colloidal stability of the resulting nano-objects in the presence of methanol or excess cationic surfactant is compared using dynamic light scattering (DLS) and transmission electron microscopy (TEM). Both types of cationic worms are evaluated as putative flocculants for aqueous dispersions of micrometer-sized silica particles using scanning electron microscopy (SEM) and laser diffraction. A critical comparison of their performance is made with various commercial soluble polymeric flocculants.

\section{Results and discussion}

\section{Synthesis of macromolecular chain transfer agents}

The PEO $_{113}$-PETTC macro-CTA used in this work was synthesized as described by Warren and co-workers,${ }^{48}$ see Scheme S1.† A commercially available poly(ethylene oxide) monomethyl ether precursor $\left(\mathrm{PEO}_{113}-\mathrm{OH}\right)$ was modified to give a mesylate adduct that was reacted with ammonia to produce a monoaminated $\mathrm{PEO}_{113}-\mathrm{NH}_{2}$ (Scheme S1a $\dagger$ ). The synthesis of the succinimide ester RAFT agent precursor, SPETTC, has been 
previously reported by Penfold and co-workers. ${ }^{62}$ The monoaminated $\mathrm{PEO}_{113}-\mathrm{NH}_{2}$ was reacted with SPETTC to produce the desired $\mathrm{PEO}_{113}$-PETTC macro-CTA. ${ }^{1} \mathrm{H}$ NMR and UV spectroscopy analysis indicated an end-group functionality of $96 \%$ and 94\%, respectively (see Fig. S1 in the ESI $\dagger$ ). THF gel permeation chromatography (GPC) analysis indicated a $M_{\mathrm{n}}$ of $4400 \mathrm{~g} \mathrm{~mol}^{-1}$ and a $M_{\mathrm{w}} / M_{\mathrm{n}}=1.08 v s$. PEO standards (see Fig. S2 $\dagger$ ). 2-(Methacryloyloxy)ethyl trimethylammonium chloride (QDMA) was selected as the polyelectrolytic monomer in view of its $\mathrm{pH}$-independent cationic character and commercial availability. A kinetic study of the RAFT aqueous solution polymerization of QDMA at $44{ }^{\circ} \mathrm{C}$ using MPETTC was undertaken at $\mathrm{pH} 4$ (see Scheme $\mathrm{S} 1 \dagger$ ). These conditions were selected to ensure protonation of the morpholine end-group of this RAFT agent and hence ensure its aqueous solubility. ${ }^{62} \mathrm{~A}$ mean degree of polymerization (DP) of 120 was targeted at $30 \% \mathrm{w} / \mathrm{w}$ solids. Fig. S3a $\uparrow$ shows the monomer conversion $v s$. time curve and corresponding semi-logarithmic plot, while Fig. S3b† shows the evolution in number-average molecular weight, $M_{\mathrm{n}}$ and dispersity $\left(M_{\mathrm{w}} / M_{\mathrm{n}}\right)$ with monomer conversion. After a brief induction period of around $10 \mathrm{~min}$, the polymerization proceeded at a relatively fast rate. More than 99\% QDMA conversion was obtained after $3 \mathrm{~h}$. The linear evolution of molecular weight with monomer conversion indicated that this polymerization has pseudo-living character and proceeded under good RAFT control, as expected. $M_{\mathrm{w}} / M_{\mathrm{n}}$ values are reduced from 1.32 to less than 1.25 during the polymerization. The non-zero $y$-intercept of $12.5 \mathrm{~kg} \mathrm{~mol}^{-1}$ is an experimental artifact that is attributed to inadequate resolution in the low molecular weight limit as a result of overlap between the polymer signal and low molecular species (monomer and/or CTA). A RAFT agent efficiency of $86 \%$ was estimated using ${ }^{1} \mathrm{H}$ NMR spectroscopy by comparing the theoretical target PQDMA DP with the experimental DP obtained at the end of the kinetic study (after allowing for the final conversion). Under identical conditions, a large batch of PQDMA PQ $_{125}$ macro-CTA with $M_{\mathrm{n}}=31800 \mathrm{~g} \mathrm{~mol}^{-1}$ and $M_{\mathrm{w}} / M_{\mathrm{n}}=1.19$ (Fig. $\mathrm{S} 2 \dagger$ ) was prepared in order to enable a detailed phase diagram to be constructed, along with the other experiments. The PQDMA DP was calculated by comparing the integrated aromatic signals assigned to the RAFT end-group at 7.2-7.4 ppm to those due to the methacrylic backbone at 0.8-2.4 ppm (Fig. S4†).

\section{Construction of $\left([1-n] \mathrm{PEO}_{113}+n \mathrm{PQDMA}_{125}\right)-\mathrm{PHPMA}_{y}$ phase diagram}

A binary mixture of $\mathrm{PEO}_{113}$ and $\mathrm{PQDMA}_{125}$ macro-CTAs was chain-extended with HPMA under RAFT aqueous dispersion polymerization conditions to produce linear cationic diblock copolymer nano-objects, see Scheme 2. A phase diagram was constructed at a constant copolymer concentration of $20 \% \mathrm{w} / \mathrm{W}$ solids (see Fig. 1) whereby the mol fraction $(n)$ of the PQDMA 125 macro-CTA was systematically varied from 0 to 0.20 while targeting DPs of 150 to 600 for the PHPMA core-forming block. For all syntheses, the final HPMA conversion exceeded 99\% and the final copolymer morphology was assigned by TEM studies. The general formula for this series of block copolymer nanoparticles is given by $\left([1-n] \mathrm{PEO}_{113}+n \mathrm{PQDMA}_{125}\right)-\mathrm{PHPMA}_{z}$, where $n$ is the mol fraction of $\mathrm{PQDMA}_{125}$ and $z$ is the target DP of the PHPMA block. Unfortunately, these linear cationic nanoparticles cannot be analyzed by GPC because there is no suitable eluent that dissolves all three blocks (i.e. hydrophilic $\mathrm{PEO}_{113}$ and PQDMA $\mathrm{P}_{125}$ plus the hydrophobic PHPMA).

In separate experiments, both $\mathrm{PEO}_{113}$ and $\mathrm{PQDMA}_{125}$ macroCTAs were chain-extended to assess their blocking efficiency. $\mathrm{PEO}_{113}$ was chain-extended with 250 units of HPMA, and in this case the resulting diblock copolymer is amenable to GPC analysis. ${ }^{48}$ In contrast, a self-blocking experiment was performed with the PQDMA $\mathrm{P}_{125}$ macro-CTA using 350 units of QDMA to target an overall DP of 475. THF and aqueous GPC analysis indicated high blocking efficiencies for both the $\mathrm{PEO}_{113}$ and $\mathrm{PQDMA}_{125}$ macro-CTAs (see Fig. S2 $\dagger$ ).

To examine the effect of conferring cationic character on the diblock copolymer nanoparticles, a series of $\mathrm{PEO}_{113}-\mathrm{PHPMA}_{z}$ diblock copolymer PISA syntheses were performed as control experiments. A pure sphere phase was obtained when targeting $\mathrm{PEO}_{113}-\mathrm{PHPMA}_{150}$ while a mixed phase of spheres and worms was identified for $\mathrm{PEO}_{113}-\mathrm{PHPMA}_{175}$, which is in good agreement with previous work by Warren et al. ${ }^{48}$ Free-standing worm gels were observed for PHPMA DPs of 220 to 225 (see Fig. 1), with a mixed phase of worms and vesicles being observed for PHPMA DPs of 250 to 300 . At a PHPMA DP of 400 , a pure vesicle phase was identified, but precipitation occurred when targeting a DP of 500. Addition of $\mathrm{PQDMA}_{125}(n=0.05)$ to such PISA syntheses has no discernible effect on the phase diagram when targeting PHPMA DPs of 225 or below. However, the worm/vesicle binary mixed phase and pure vesicle phase are no longer observed above this critical PHPMA DP. Instead, only rather ill-defined copolymer morphologies are obtained, such as mixed phases of worms and lamella-like sheets or mixtures of spheres, vesicles and tubular vesicles (see Fig. S5 $\dagger$ ). However, precipitation does not occur at a PHPMA DP of 500 or 600 when PQDMA 125 is incorporated as a supplementary stabilizer block. Presumably, the polyelectrolytic character of this macro-CTA boosts the steric stabilization conferred by the non-ionic $\mathrm{PEO}_{113}$, thus facilitating the formation of colloidally stable nano-objects (see Fig. S5 $\dagger$ ). Increasing the $\mathrm{PQDMA}_{125} \mathrm{~mol}$ fraction (from $n=0.05$ to $n=0.10$ ) in this PISA formulation has a relatively modest effect on the phase diagram. The only discernible change is at a PHPMA DP of 200, where a sphere/worm mixed phase is observed, indicating narrowing of the worm phase space. A representative TEM image of linear $\left(0.9 \mathrm{PEO}_{113}+0.1 \mathrm{PQDMA}_{125}\right)$ PHPMA $_{225}$ worms is shown in Fig. $1 \mathrm{~b}$. A pure worm phase is no longer observed on increasing $n$ up to 0.125 .

This is consistent with recent work by Williams and co-workers, ${ }^{\mathbf{8 1}}$ who utilized poly(glycerol monomethacrylate) (PGMA) instead of $\mathrm{PEO}_{113}$ as a non-ionic stabilizer block in combination with a $\mathrm{PQDMA}_{95}$ macro-CTA to produce cationic thermoresponsive worm gels with weak anti-microbial activity. Thus, if a pure worm phase is desired, the maximum proportion of PQDMA $\mathrm{P}_{125}$ that can be incorporated into the present PISA formulation is $n=0.10$. This constraint arises because the worm phase is relatively narrow, as reported previously. ${ }^{82}$ Aqueous electrophoresis was used to characterize the cationic 


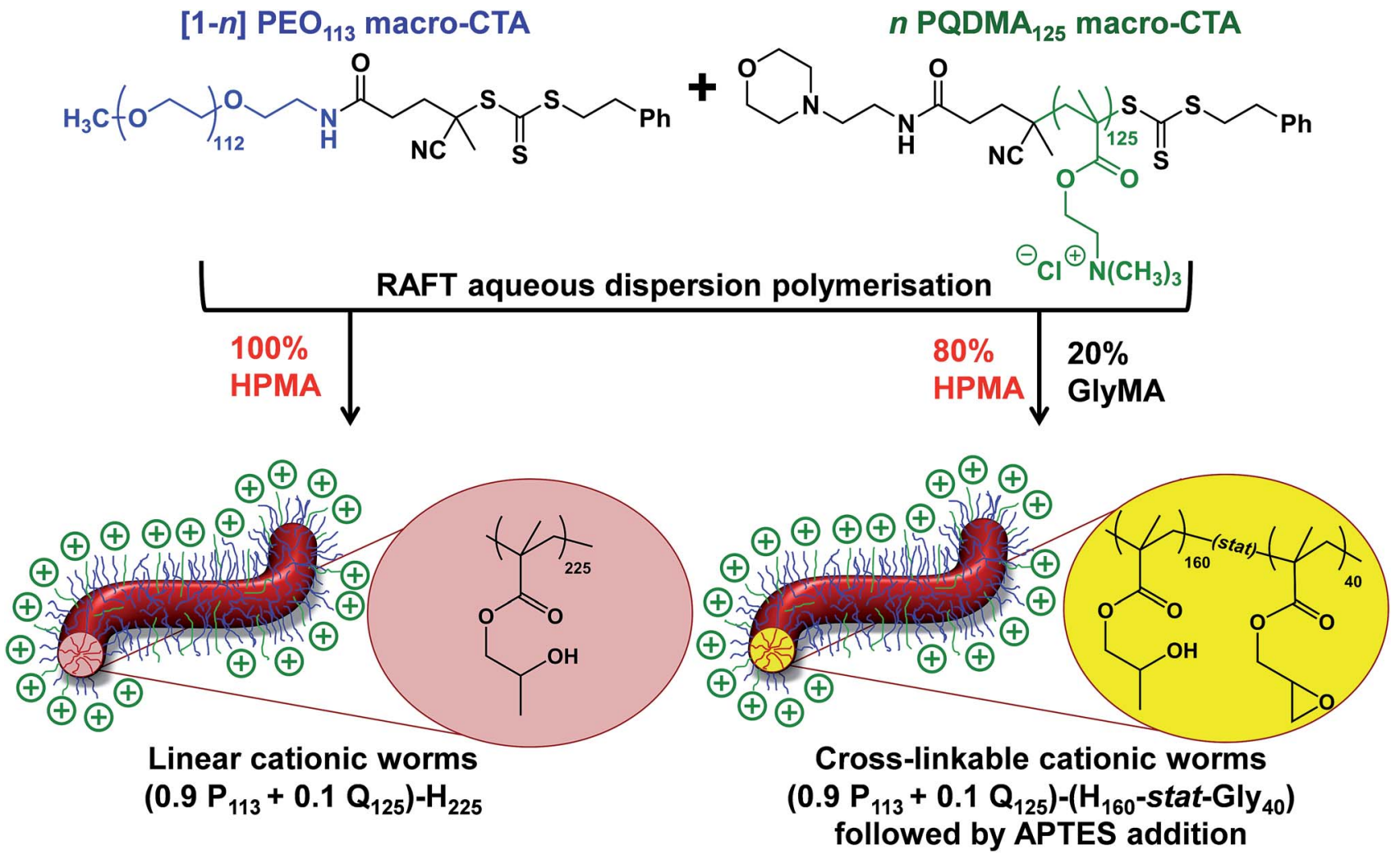

Scheme 2 The synthesis of either linear or core cross-linked cationic diblock copolymer worms was achieved via RAFT aqueous dispersion homopolymerization of 2-hydroxypropyl methacrylate (HPMA) or statistical copolymerization of HPMA with glycidyl methacrylate (GlyMA) using a binary mixture of poly(ethylene oxide) and poly(2-(methacryloyloxy)ethyl trimethylammonium chloride) (PQDMA) chain transfer agents. Here $n$ represents the mole fraction of PQDMA 125 in the binary mixture of PQDMA 125 and $\mathrm{PEO}_{113}$ macro-CTAs. For brevity, $\mathrm{H}$ and Gly denote HPMA and GlyMA, respectively and $P$ and $Q$ refer to the $P E O$ and PQDMA stabilizer blocks.

character of three pure diblock copolymer worms at a fixed PHPMA DP of 225 (see Fig. 2). As expected, the PEO $_{113}$-PHPMA 225 copolymer worm control exhibited a zeta potential of approximately zero across the entire $\mathrm{pH}$ range studied. Introduction of $\mathrm{PQDMA}_{125}$ into the stabilizer block $(n=0.05)$ led to initially weak cationic character, as indicated by a pH-independent zeta potential of approximately $+13 \mathrm{mV}$. However, a relatively high zeta potential of $+35 \mathrm{mV}$ was observed on doubling the mol fraction of $\operatorname{PQDMA}_{125}(n=0.10)$ and again there was no discernible change over a wide $\mathrm{pH}$ range. In all cases, simultaneous DLS studies confirmed that there was no change in the 'sphere-equivalent' hydrodynamic diameter on varying the solution $\mathrm{pH}$, suggesting that the original worm morphology was retained during these electrophoresis studies.

\section{Covalent cross-linking and colloidal stability of cationic diblock copolymer worms}

Lovett et al. reported that 3-aminopropyl triethoxysilane (APTES) can be used to cross-link epoxy-functionalized worms via a post-polymerization protocol. ${ }^{76}$ Worm core cross-linking involves reaction of the epoxy groups on the GlyMA residues with APTES, with concomitant hydrolysis to form silanol groups that condense with other silanol groups and/or secondary hydroxyl groups located on neighboring HPMA residues (see Scheme S2 $\dagger$ ). These reactions lead to extensive cross-linking within the worm cores. ${ }^{1} \mathrm{H}$ NMR was used to monitor this complex process and it was found that epoxide ring-opening and hydrolysis/condensation occurred on comparable time scales. ${ }^{76}$ Such covalently-stabilized non-ionic worms remained colloidally stable in the presence of either methanol or anionic surfactant, whereas the linear precursor worms underwent rapid dissociation under the same conditions. An increase in storage modulus $\left(G^{\prime}\right)$ was observed after core cross-linking, which is presumably the result of an increase in the worm persistence length. ${ }^{76}$

In view of these prior observations, we decided to examine the PISA synthesis of core cross-linked cationic diblock copolymer worms and assess their colloidal stability in the presence of either methanol or a well-known cationic surfactant, cetyltrimethylammonium bromide (CTAB). The mol fraction, $n$, of PQDMA $_{125}$ was fixed at 0.10 in order to maximize the cationic character of the copolymer nanoparticles while maintaining a pure worm phase. The PHPMA core-forming block was replaced with a statistical copolymer comprising $80 \mathrm{~mol} \%$ HPMA and 20 mol\% GlyMA. However, introducing the GlyMA comonomer led to a subtle change in the phase diagram, with a mixed phase of worms and vesicles being observed instead of the desired pure worm phase (Fig. S6 †). Thus the overall DP of the core-forming block was adjusted from 225 to 200 to 


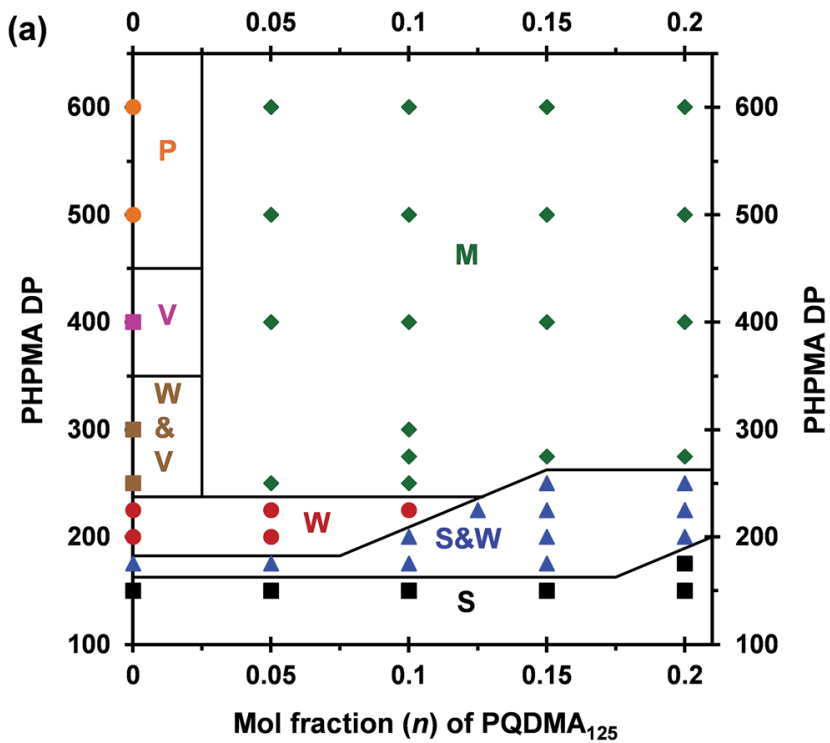

(b)

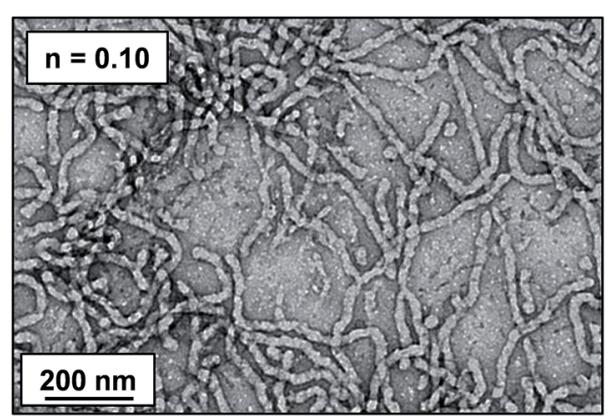

Fig. 1 (a) Phase diagram constructed for the RAFT aqueous dispersion polymerization of HPMA at a fixed copolymer concentration of $20 \%$ $\mathrm{W} / \mathrm{W}$ solids at $50{ }^{\circ} \mathrm{C}$ using a binary mixture of $\mathrm{PEO}_{113}-\mathrm{PETTC}$ and $\mathrm{PQDMA}_{125}$ macro-CTAs $[\mathrm{S}=$ spheres, $\mathrm{W}=$ worms, $\mathrm{V}=$ vesicles, $M=$ mixed phase and $P=$ precipitate]. (b) Representative TEM image for linear cationic $\left(0.9 \mathrm{PEO}_{113}+0.1 \mathrm{PQDMA} \mathrm{A}_{125}\right)-\mathrm{PHPMA}_{225}$ worms.

compensate for the presence of the GlyMA comonomer. A very high comonomer conversion $(>99 \%)$ was achieved to afford well-defined linear $\left(0.9 \mathrm{PEO}_{113}+0.1 \mathrm{PQDMA}_{125}\right)-\mathrm{P}\left(\mathrm{HPMA}_{160}\right.$-statGlyMA $_{40}$ ) diblock copolymer worms. Unfortunately, PISA synthesis at $20 \% \mathrm{w} / \mathrm{w}$ solids produced a rather strong copolymer gel, which made APTES dissolution for post-polymerization cross-linking somewhat problematic. Hence this worm gel was diluted to $7.5 \% \mathrm{w} / \mathrm{w}$ solids using deionized water prior to APTES addition, followed by gentle stirring for $24 \mathrm{~h}$ at room temperature. TEM studies confirmed the presence of both linear $\left(0.9 \mathrm{PEO}_{113}+0.1 \mathrm{PQDMA}_{125}\right)-\mathrm{P}\left(\mathrm{HPMA}_{160}\right.$-stat-GlyMA $\left.{ }_{40}\right)$ diblock copolymer worms and cross-linked $\left(0.9 \mathrm{PEO}_{113}+0.1 \mathrm{PQDMA}_{125}\right)$ $\mathrm{P}\left(\mathrm{HPMA}_{160}\right.$-stat-GlyMA ${ }_{40}$ ) diblock copolymer worms (see Fig. 3 ). Chambon and co-workers ${ }^{71}$ reported using DLS and TEM to assess the colloidal stability of block copolymer vesicles in the presence of various aqueous surfactant solutions. Herein we utilize the same approach to examine the colloidal stability of both linear and core cross-linked cationic worms in the presence of either methanol (which is a good solvent for the coreforming block) or $0.1 \% \mathrm{w} / \mathrm{w}$ CTAB. A $0.1 \% \mathrm{w} / \mathrm{w}$ CTAB solution

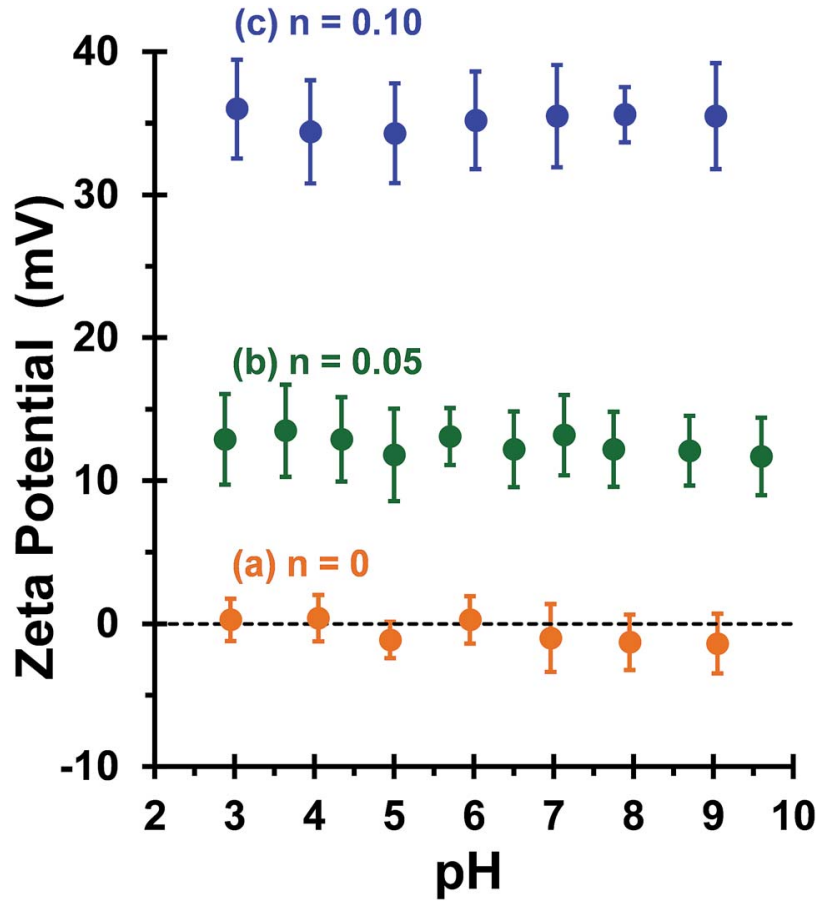

Fig. 2 Zeta potential vs. $\mathrm{pH}$ curves obtained for a series of ([1 $-n]$ $\left.\mathrm{PEO}_{113}+n \mathrm{PQDMA}_{125}\right)-\mathrm{PHPMA}_{225}$ linear diblock copolymer worms prepared at $20 \% \mathrm{w} / \mathrm{w}$ solids by the RAFT aqueous dispersion polymerization of HPMA at $50{ }^{\circ} \mathrm{C}$, where (a) $n=0$, (b) $n=0.05$ and (c) $n=0.10$. Zeta potentials were determined at $20{ }^{\circ} \mathrm{C}$ for $0.1 \% \mathrm{w} / \mathrm{w}$ copolymer dispersions in the presence of $1 \mathrm{mM} \mathrm{KCl}$. Error bars are equivalent to one standard deviation. The aqueous dispersion $\mathrm{pH}$ was adjusted using either $0.1 \mathrm{M}$ or $1 \mathrm{M} \mathrm{HCl}$.

corresponds to a concentration of $2.7 \mathrm{mM}$, which is above the critical micelle concentration for CTAB reported in the literature. ${ }^{83,84}$ Table $\mathrm{S} 1 \uparrow$ summarizes the intensity-average diameters, zeta potentials and the derived count rates obtained for linear and cross-linked cationic worms (i) dispersed in mildly alkaline aqueous solution ( $\mathrm{pH}$ 9), (ii) in the presence of $0.1 \% \mathrm{w} / \mathrm{w} \mathrm{CTAB}$ (also at pH 9), or (iii) as a methanolic dispersion. It is important to note that the 'sphere-equivalent' hydrodynamic diameter reported by DLS does not correspond to either the mean worm length or the mean worm width. Notwithstanding this limitation, this sizing technique suggests that the dimensions of the linear and cross-linked worms at pH 9 are comparable.

Furthermore, mean zeta potentials obtained for the crosslinked and linear worms are very similar (approximately $+35 \mathrm{mV}$ ). The linear worm dispersion diluted in methanol has a very low normalized light scattering intensity, which suggests worm dissociation under these conditions. In contrast, the relatively high light scattering intensity observed for crosslinked worms in the same solvent indicates that the original vermicious morphology is preserved under these conditions. The slightly higher 'sphere-equivalent' diameter for the crosslinked worms in methanol compared to the same worms in water $(240 \mathrm{~nm} v s .216 \mathrm{~nm})$ most likely indicates some degree of worm swelling, which would also account for the modest (ca. 10\%) reduction in the light scattering intensity. Thus 

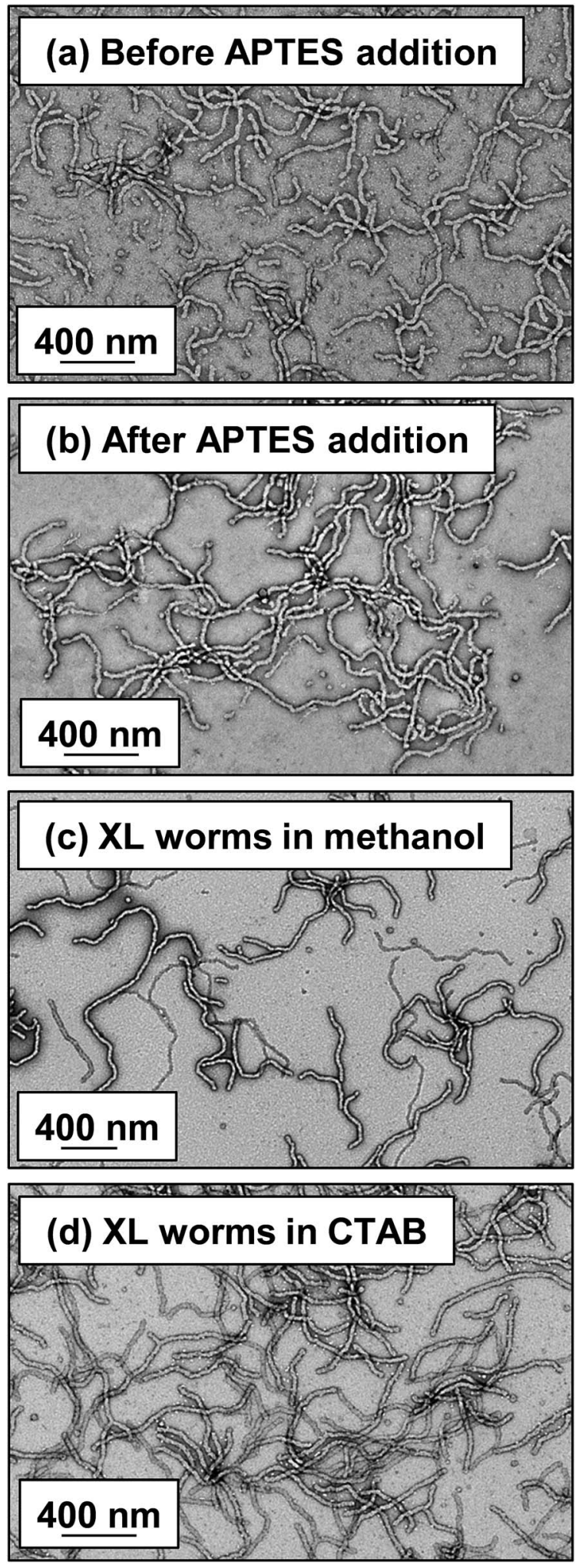

Fig. 3 Representative TEM images recorded for $0.1 \% \mathrm{w} / \mathrm{w}$ copolymer worm dispersions dried at $\mathrm{pH}$ 9: (a) $\left(0.9 \mathrm{PEO}_{113}+0.1 \mathrm{PQDMA}_{125}\right)$ $\mathrm{P}\left(\mathrm{HPMA}_{160}\right.$-stat-GlyMA $\left.\mathrm{A}_{40}\right)$ worms pre-APTES addition, (b) core crosslinked $\left(0.9 \mathrm{PEO}_{113}+0.1 \mathrm{PQDMA} \mathrm{A}_{125}\right)-\mathrm{P}\left(\mathrm{HPMA}_{160}\right.$-stat-GlyMA 40$)$ worms after APTES addition, and the same copolymer worms in the presence of (c) $0.1 \% \mathrm{w} / \mathrm{w}$ CTAB and (d) diluted from $7.5 \% \mathrm{w} / \mathrm{w}$ copolymer to $0.1 \%$ $\mathrm{w} / \mathrm{w}$ copolymer using methanol [abbreviations: $\mathrm{XL}=$ core cross-linked and $\mathrm{CTAB}=$ cetyltrimethylammonium bromide]. successful cross-linking of the worm cores prevents molecular dissolution occurring under these conditions. It is also instructive to compare the linear and cross-linked worms exposed to the presence of $0.1 \% \mathrm{w} / \mathrm{w}$ CTAB. The relatively low normalized intensity observed for the former dispersion suggests near-molecular dissolution of the linear worms, whereas the cross-linked worms clearly survive the CTAB challenge. Indeed, TEM studies of the corresponding dried dispersions confirm that the cross-linked worms survive exposure to $0.1 \% \mathrm{w} / \mathrm{w}$ CTAB or dilution from $20 \% \mathrm{w} / \mathrm{w}$ to $0.1 \% \mathrm{w} / \mathrm{w}$ solids using methanol co-solvent (see Fig. 3).

\section{Flocculation of micrometer-sized silica particles}

Bridging flocculation typically involves the adsorption of a high molecular weight water-soluble polymer onto two or more relatively small colloidal nanoparticles, which promotes their aggregation. For example, Solberg and co-workers reported using high molecular weight polyacrylamide for the flocculation of $20 \mathrm{~nm}$ aqueous silica sols. ${ }^{8}$ Other well-known flocculants include high molecular weight poly(ethylene oxide) or poly( $N$-vinylpyrrolidone) ${ }^{85,86}$ Similarly, Mabire et al. found that cationic polyelectrolytes can act as highly effective flocculants for $125 \mathrm{~nm}$ anionic silica particles. ${ }^{87}$ However, for the flocculation of much larger (micrometer-sized) particles, the bridging flocculation mechanism is likely to fail. This is because the markedly different length scales between the particles and the soluble polymer chains favour steric stabilization (i.e. the soluble polymer adsorbs onto and fully coats individual particles, see Scheme 1). In the present study, both linear and crosslinked cationic worms were evaluated as putative flocculants for micrometer-sized silica particles, with various high molecular weight water-soluble polymers being used as negative controls.

In principle, core cross-linking should make the worm morphology much more robust. Moreover, stiffer worms should be obtained with a greater mean persistence length, which should aid worm adsorption onto multiple silica particles. In initial experiments, zeta potential vs. $\mathrm{pH}$ curves were constructed for $0.1 \% \mathrm{w} / \mathrm{w}$ aqueous dispersions of linear worms, core cross-linked worms and silica particles. The bare silica particles exhibit a volume-average diameter, $D_{[4 / 3]}$ of $1.0 \mu \mathrm{m}$, as judged by laser diffraction studies. A zeta potential of $-69 \mathrm{mV}$ was observed for these silica particles at $\mathrm{pH} 9$, whereas the linear and cross-linked cationic worms had comparable zeta potentials of $+35 \mathrm{mV}$ and $+34 \mathrm{mV}$, respectively (see Fig. 4). As expected, both worm dispersions exhibited $\mathrm{pH}$-independent electrophoretic behaviour, whereas the zeta potential for the $1.0 \mu \mathrm{m}$ silica particles gradually decreased to $-20 \mathrm{mV}$ at $\mathrm{pH} 2.8$. Thus the flocculation study was performed at $\mathrm{pH} 9$ in order to maximize the electrostatic interaction. All flocculation studies were conducted using $1.0 \% \mathrm{w} / \mathrm{w}$ silica. The adsorbed amount (i.e. the worm mass per unit surface area of silica) was systematically varied in order to assess the effectiveness of the cationic worms as flocculants for the silica particles. The specific surface area, $A_{\mathrm{s}}$, of these silica particles can be calculated using $A_{\mathrm{s}}=3 /\left(\rho_{\text {silica }} R\right)$, where $\rho_{\text {silica }}$ and $R$ are the density and mean radius of the silica particles, respectively. The solid-state density 


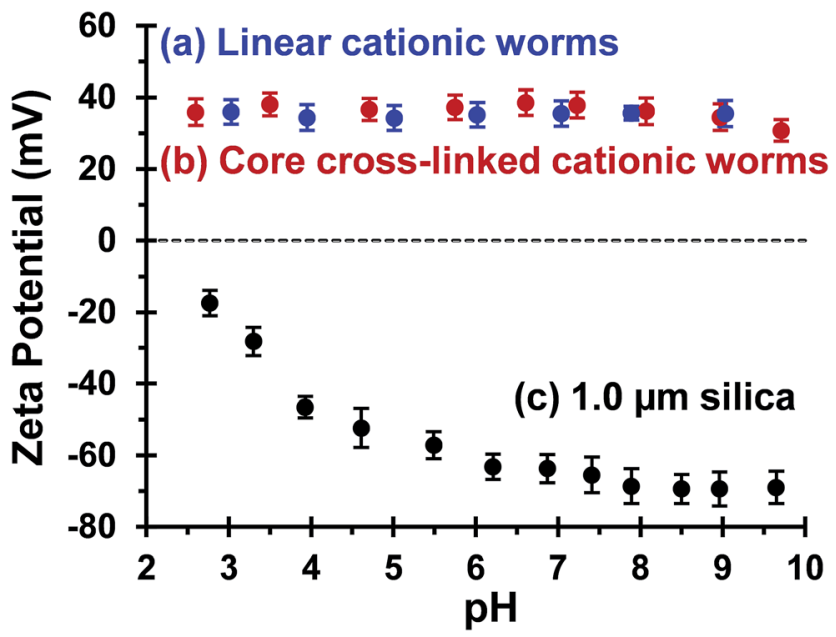

Fig. 4 Zeta potential vs. pH curves recorded for (a) linear (0.9PEO $113+$ 0.1PQDMA $\left.A_{125}\right)-$ PHPMA $_{225}$ worms, (b) core cross-linked $\left(0.9 \mathrm{PEO}_{113}+\right.$ $\left.0.1 P Q D M A_{125}\right)-P\left(H_{P M A} M_{160}\right.$-stat-GlyMA 40$)$ worms and (c) $1.0 \mu \mathrm{m}$ silica particles. The linear worm data set is taken from Fig. 2 to enable direct comparison. Measurements were conducted at $20{ }^{\circ} \mathrm{C}$ on $0.1 \% \mathrm{w} / \mathrm{w}$ dispersions in the presence of $1 \mathrm{mM}$ background $\mathrm{KCl}$. The dispersion $\mathrm{pH}$ was adjusted by addition of either $1.0 \mathrm{M}$ or $0.1 \mathrm{M} \mathrm{HCl}$.

of the $1.0 \mu \mathrm{m}$ diameter silica particles, $\rho_{\text {silica, }}$, was found to be $2.03 \mathrm{~g} \mathrm{~cm}^{-3}$ by helium pycnometry. Using this density, $A_{\mathrm{s}}$ is estimated to be $2.9 \mathrm{~m}^{2} \mathrm{~g}^{-1}$.

These silica particles were added to the cross-linked cationic worms at nominal adsorbed amounts of $0.1 \mathrm{mg} \mathrm{m}^{-2}, 2.1 \mathrm{mg}$ $\mathrm{m}^{-2}$ and $4.8 \mathrm{mg} \mathrm{m}^{-2}$. At $0.1 \mathrm{mg} \mathrm{m}^{-2}$, laser diffraction studies indicated no significant change in $D_{[4 / 3]}$ for both the linear and the cross-linked cationic worms, confirming that essentially no flocculation of the $1.0 \mu \mathrm{m}$ silica particles occurred under these conditions (see Fig. 5a).

At a higher nominal adsorbed amount of $2.1 \mathrm{mg} \mathrm{m}^{-2}$, laser diffraction indicated a $D_{[4 / 3]}$ of $3 \mu \mathrm{m}$ for the linear cationic worms, suggesting only rather weak flocculation (Fig. 5c). However, the cross-linked cationic worms act as a highly effective flocculant, with a $D_{[4 / 3]}$ of $28 \mu \mathrm{m}$ being observed (Fig. $5 \mathrm{~b}$ ). Increasing the nominal adsorbed amount to $4.8 \mathrm{mg} \mathrm{m}^{-2}$ confirmed the superior flocculation performance of cross-linked worms compared to that of the linear worms, with $D_{[4 / 3]}$ diameters of $25 \mu \mathrm{m}$ and $3 \mu \mathrm{m}$ being observed respectively (compare Fig. 5e and f). SEM studies were conducted on $1.0 \mu \mathrm{m}$ silica particles before and after exposure to either linear or crosslinked cationic worms. The pristine $1.0 \mu \mathrm{m}$ silica particles (Fig. 6a) are spherical, uniform in size and have a smooth surface morphology. At a nominal adsorbed amount of $2.1 \mathrm{mg} \mathrm{m}^{-2}$, SEM studies provide no evidence for the linear worms surviving electrostatic adsorption onto the silica surface (Fig. 6b). Instead, only relatively small, pseudo-spherical structures can be observed. However, when cross-linked worms are used under the same conditions, intact adsorbed worms are clearly discernible at the silica particle surface (Fig. 6c). Using a nominal adsorbed amount of $4.8 \mathrm{mg} \mathrm{m}^{-2}$ leads to similar observations, but higher surface coverage of the silica particles is achieved in each case (compare Fig. 6b with 6d and also Fig. 6c with 6e).
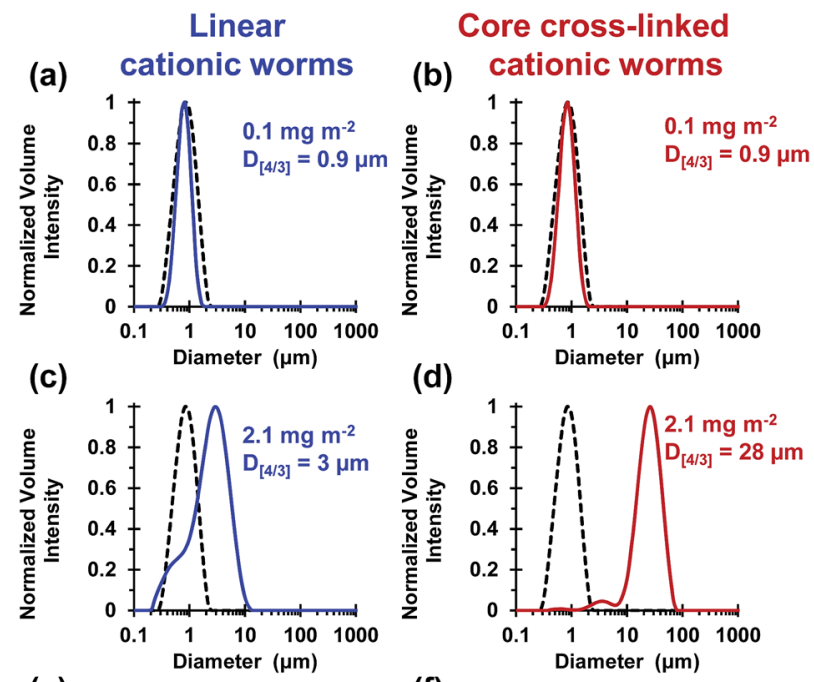

\section{(e)}

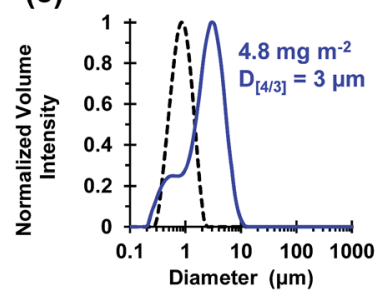

Fig. 5 Volume-average particle size distributions obtained via laser diffraction for the attempted flocculation of $1.0 \mu \mathrm{m}$ silica at $\mathrm{pH} 9$ using either linear $\left(0.9 \mathrm{PEO}_{113}+0.1 \mathrm{PQDMA}_{125}\right)-\mathrm{PHPMA}_{225}$ worms (blue traces) or core cross-linked (0.9PEO $\left.\mathrm{PE}_{113}+0.1 \mathrm{PQDMA}_{125}\right)-\mathrm{P}\left(\mathrm{HPMA}_{160^{-}}\right.$ stat-GlyMA $\mathrm{AO}_{40}$ ) worms (red traces) at adsorbed amounts of (a, b) $0.1 \mathrm{mg} \mathrm{m}^{-2}$ (c, d) $2.1 \mathrm{mg} \mathrm{m}^{-2}$ and (e, f) $4.8 \mathrm{mg} \mathrm{m}^{-2}$, respectively. The black dotted traces represent the volume-average particle size distribution obtained for the pristine $1.0 \mu \mathrm{m}$ silica particles in the absence of any worms.

Close inspection of Fig. $6 \mathrm{f}$ indicates that some of the crosslinked cationic worms span between adjacent silica particles (see red arrows in Fig. 6f). This provides direct evidence that the particle aggregation observed by laser diffraction is indeed the result of a bridging flocculation mechanism.

Cross-linked worms are much more effective flocculants than linear worms because they are much more robust: covalent stabilization of the worm cores is essential to preserve the original copolymer morphology after electrostatic adsorption of the cationic worms onto the anionic silica particles. In striking contrast, the linear cationic worms break up following their adsorption onto the relatively massive silica particles to form two distinct populations of (mainly) non-ionic $\mathrm{PEO}_{113}-\mathrm{PHPMA}_{225}$ and (mainly) cationic PQDMA $_{125}-\mathrm{PHPMA}_{225}$ nanoparticles, with each possessing a pseudo-spherical morphology (see Scheme S3†). The hydrophobic nature of the core-forming PHPMA block drives formation of the linear worms during PISA. However, this weak physical interaction is clearly insufficient to maintain the original morphology once these cationic worms adsorb onto the anionic silica particles.

Image J software was used to assess worm dimensions from TEM images. Analysis of 50 worms indicated a mean worm 

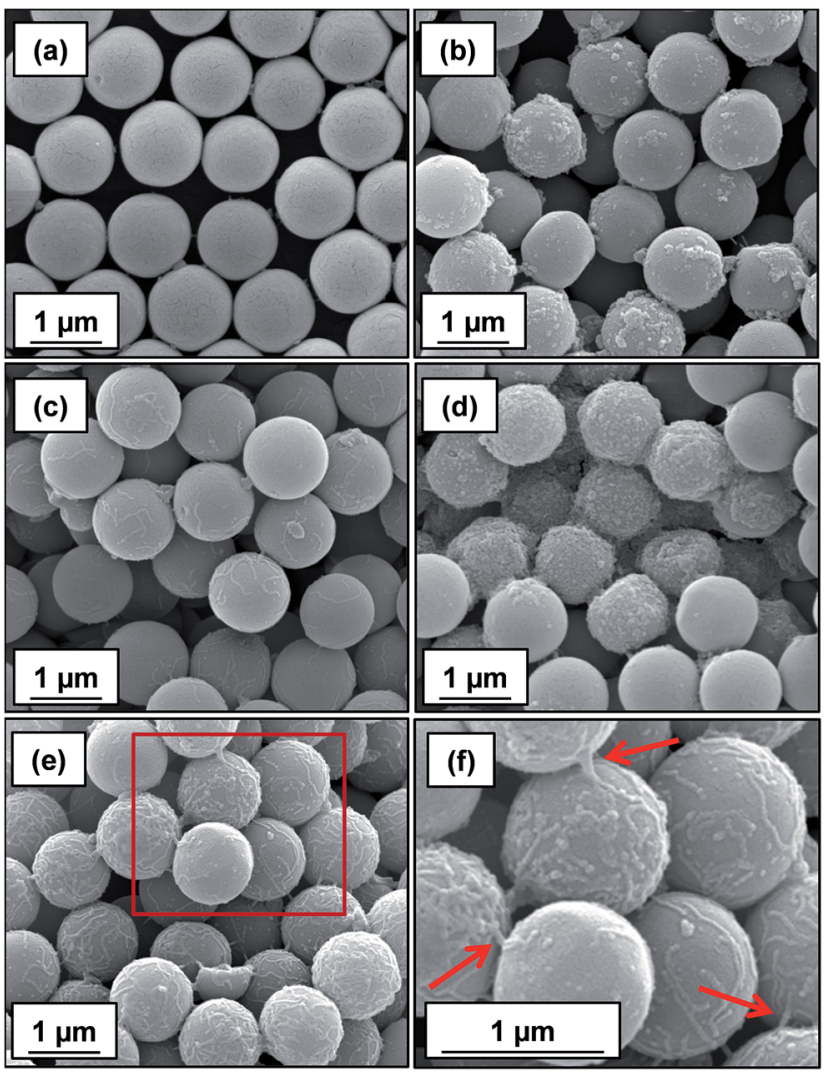

Fig. 6 SEM images obtained for (a) bare $1.0 \mu \mathrm{m}$ silica, (b) silica plus linear cationic worms and (c) silica plus cross-linked cationic worms prepared at a nominal adsorbed amount of $2.1 \mathrm{mg} \mathrm{m}^{-2}$, respectively. Images shown in (d) and (e) correspond to $1.0 \mu \mathrm{m}$ silica particles in the presence of either linear or cross-linked cationic worms at a nominal adsorbed amount of $4.8 \mathrm{mg} \mathrm{m}^{-2}$. (f) Magnified image of the area indicated by the red square shown in (e), confirming the presence of cross-linked cationic worms adsorbed intact at the silica particle surface; this provides direct experimental evidence for the bridging flocculation mechanism indicated by laser diffraction studies (see Fig. 5). In each case, worms were adsorbed onto the silica particles ([silica $]_{0}=1.0 \% \mathrm{w} / \mathrm{w}$ ) at $\mathrm{pH} 9$ followed by drying at $20{ }^{\circ} \mathrm{C}$ overnight prior to SEM inspection.

length, $L_{\mathrm{w}}$, of $956 \mathrm{~nm}$ and a mean worm radius, $r_{\mathrm{w}}$, of $15 \mathrm{~nm}$. If the worm morphology is approximated to that a cylinder of volume $V$ (where $V=\pi r_{\mathrm{w}} 2 L_{\mathrm{w}}$ ) and taking the worm density, $\rho_{\mathrm{w}}$, to be that of the PHPMA core-forming block $\left(1.15 \mathrm{~g} \mathrm{~cm}^{-3}\right)$, we estimate the mean mass, $m$, (where $m=\rho_{\mathrm{w}} V$ ) of a single worm to be $7.77 \times 10^{-16} \mathrm{~g}$. Note that the mass, $M$, of a single $1.0 \mu \mathrm{m}$ silica particle, using $M=\rho_{\text {silica }} \times 4 / 3 \pi R^{3}$ (where $R$ is the silica particle radius), is calculated to be $1.12 \times 10^{-12} \mathrm{~g}$, which is approximately 1450 times greater than that of a single worm. Thus the linear cationic worms are simply unable to survive the strong torsional forces exerted on them by the much more massive silica particles during Brownian motion. Electrostatic interactions lead to strong adsorption of the cationic worms onto the anionic silica particles, so the failure mechanism involves disruption of the physical van der Waals forces between the weakly hydrophobic PHPMA chains within the worm cores. In order to gain further mechanistic insight, an
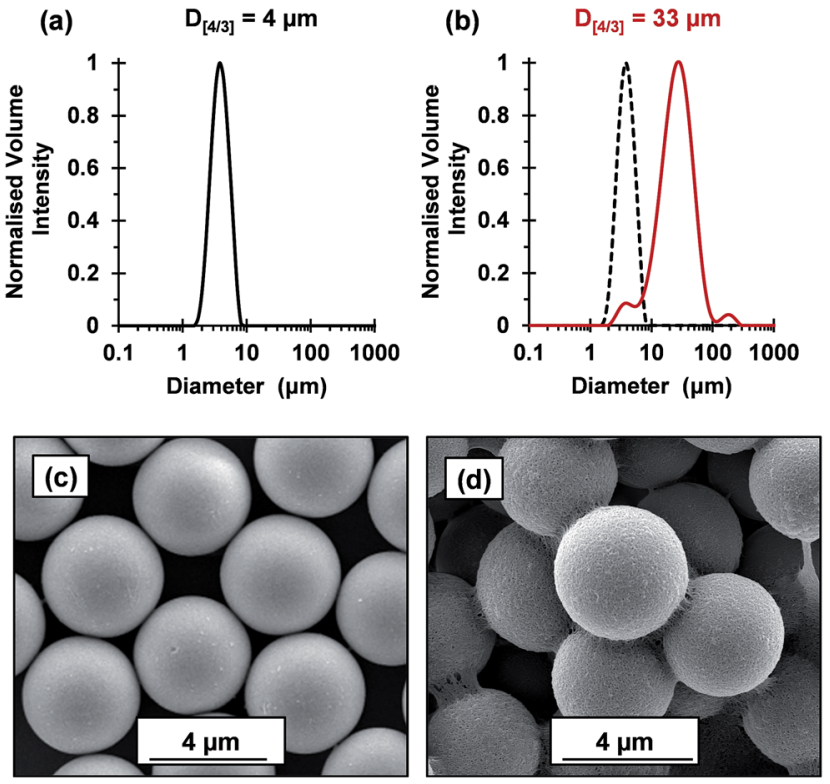

Fig. 7 Volume-average particle size distributions obtained via laser diffraction for (a) pristine $4 \mu \mathrm{m}$ silica particles and (b) $\left(0.9 \mathrm{PEO}_{113}+\right.$ $\left.0.1 P Q D M A_{125}\right)-P\left(H_{P M A} A_{160}\right.$-stat-GlyMA 40$)$ cross-linked worms adsorbed onto $4 \mu \mathrm{m}$ silica particles at a nominal adsorbed amount of $88 \mathrm{mg} \mathrm{m}^{-2}$. Representative SEM images are shown for (c) pristine $4 \mu \mathrm{m}$ silica particles and (d) the above cross-linked worms adsorbed onto these silica particles, which supports the suggested bridging flocculation mechanism.

aqueous dispersion comprising a binary mixture of $1.0 \mu \mathrm{m}$ silica particles plus linear copolymer worms prepared at a nominal adsorbed amount of $4.8 \mathrm{mg} \mathrm{m}^{-2}$ was centrifuged at $6000 \mathrm{rpm}$ for $1 \mathrm{~h}$. After careful removal of the aqueous supernatant, the sedimented silica particles were redispersed in water at $\mathrm{pH} 9$. Aqueous electrophoresis studies conducted at $\mathrm{pH} 9$ indicated a zeta potential of only $-17 \mathrm{mV}$, which is significantly lower than that of the original silica particles (see Fig. 4). This suggests that the pseudo-spherical particles that remain on the surface of the silica particles (see Fig. 6d) comprise mainly cationic $\mathrm{PQDMA}_{125}-\mathrm{PHPMA}_{225}$ chains. According to Semsarilar et al., copolymer nanoparticles comprising mainly $\mathrm{PQDMA}_{125}-\mathrm{PHPMA}_{225}$ chains would be expected to form spheres, rather than worms. ${ }^{80}$ In addition, adsorption of nonionic $\mathrm{PEO}_{113}-\mathrm{PHPMA}_{225}$ nanoparticles at the silica surface may also occur. However, DLS studies of the aqueous supernatant solution obtained after sedimentation of the silica particles indicated a mean hydrodynamic particle diameter of $85 \mathrm{~nm}$ (DLS polydispersity $=0.19$ ), with aqueous electrophoresis studies indicating a weakly negative zeta potential of $-7 \mathrm{mV}$. TEM studies of this dried supernatant confirmed a pseudospherical morphology (Fig. S7†). Based on findings reported by Warren and co-workers, $\mathrm{PEO}_{113}$-PHPMA 225 was expected to selfassemble to form worms in aqueous solution. ${ }^{48}$ Inspecting Fig. 1, this is indeed the case. However, for the highly dilute copolymer concentrations utilized in these flocculation studies, multiple sphere-sphere fusion (which is the critical first step for worm formation ${ }^{88}$ ) cannot occur, which leads to a kineticallytrapped spherical morphology (see Fig. 1). Thus there is strong 
Table 1 Summary of the volume-average particle diameters obtained via laser diffraction after the attempted flocculation of a $1.0 \% \mathrm{w} / \mathrm{w}$ aqueous dispersion of $1.0 \mu \mathrm{m}$ silica particles at $\mathrm{pH} 9$ using four commercially available water-soluble polymers as putative flocculants

Volume-average diameter $(\mu \mathrm{m})$ via laser diffraction using various adsorbed amounts of polymer per unit area of silica

\begin{tabular}{|c|c|c|c|c|c|}
\hline Commercial polymer & $M_{\mathrm{w}}\left(\mathrm{g} \mathrm{mol}^{-1}\right)$ & $2.1 \mathrm{mg} \mathrm{m}^{-2}$ & $4.8 \mathrm{mg} \mathrm{m}^{-2}$ & $17.2 \mathrm{mg} \mathrm{m}^{-2}$ & $34.3 \mathrm{mg} \mathrm{m}^{-2}$ \\
\hline Poly(ethylene oxide) & 4000000 & 2 & 3 & 3 & 3 \\
\hline Polyacrylamide & 6000000 & 1 & 1 & 1 & 3 \\
\hline Poly( $N$-vinylpyrrolidone $)$ & 1300000 & 2 & 2 & 2 & 3 \\
\hline Poly(diallyldimethylammonium chloride) & 500000 & 1 & 1 & 1 & 3 \\
\hline
\end{tabular}

experimental evidence to support the in situ disintegration of the linear cationic worms during their adsorption onto micrometer-sized silica particles, as summarized in Scheme S3. $\dagger$ It is emphasized that this mechanism does not apply to the cross-linked cationic worms, since covalent stabilization is sufficient to enable their survival after adsorption onto the relatively massive silica particles. This accounts for the marked difference in performance for these two putative bridging flocculants.

The flocculation performance of the cross-linked cationic worms was further examined by attempting flocculation of $4 \mu \mathrm{m}$ silica particles at $\mathrm{pH}$ 9. At this $\mathrm{pH}$, the silica spheres exhibit a zeta potential of $-74 \mathrm{mV}$. Given that the $A_{\mathrm{s}}$ of these silica spheres is $0.72 \mathrm{~m}^{2} \mathrm{~g}^{-1}$, the silica concentration was increased to $4.0 \% \mathrm{w} / \mathrm{w}$ to maintain a constant silica surface area. No flocculation was observed when using nominal adsorbed amounts of $2.1 \mathrm{mg} \mathrm{m}^{-2}$ and $4.8 \mathrm{mg} \mathrm{m}^{-2}$, which had been sufficient to flocculate the $1.0 \mu \mathrm{m}$ silica particles. Thus, this parameter was increased to $88 \mathrm{mg} \mathrm{m}^{-2}$ (Fig. 7). Laser diffraction studies confirmed an increase in apparent volume-average diameter from $4 \mu \mathrm{m}$ for the original silica particles up to $33 \mu \mathrm{m}$ in the presence of the cross-linked cationic worms. SEM studies indicated that these worms adsorb intact at the silica surface with relatively high surface coverage and readily identifiable worm bridges between adjacent silica particles. It is perhaps noteworthy that the $4.0 \mu \mathrm{m}$ silica particles were normally added to the cross-linked cationic worms. However, similarly strong flocculation was also observed if this order of addition was reversed (see Fig. S8 $\dagger$ ). Comparable results were also obtained when using the $1.0 \mu \mathrm{m}$ silica particles (data not shown). Moreover, such cross-linked cationic worms were also able to flocculate $8 \mu \mathrm{m}$ silica particles (data not shown).

For comparative purposes, four high molecular weight commercial water-soluble polymers were examined as potential flocculants for the $1.0 \mu \mathrm{m}$ silica particles at $\mathrm{pH}$ 9. These polymers were poly(ethylene oxide) (PEO; $M_{\mathrm{w}}=4000000 \mathrm{~g} \mathrm{~mol}^{-1}$ ), polyacrylamide (PA; $\left.M_{\mathrm{w}}=6000000 \mathrm{~g} \mathrm{~mol}^{-1}\right)$, poly $(N$-vinylpyrrolidone) (PVP; $M_{\mathrm{w}}=1300000 \mathrm{~g} \mathrm{~mol}{ }^{-1}$ ) and poly(diallyldimethylammonium chloride) (PDADMAC; $M_{\mathrm{w}}=500000$ $\mathrm{g} \mathrm{mol}^{-1}$ ), see Table 1 . The apparent volume-average particle diameters of the silica particles obtained after addition of each of these four commercial polymers to $1.0 \mu \mathrm{m}$ silica particles at pH 9 at nominal adsorbed amounts of $2.1,4.8,17.2$ or $34.3 \mathrm{mg}$ $\mathrm{m}^{-2}$ are also summarized in Table 1. Little or no flocculation was observed in all cases. Laser diffraction size distributions are either unimodal or bimodal, with peaks at $1.0 \mu \mathrm{m}$ and approximately $4 \mu \mathrm{m}$ being observed (see Figs. S9-S12†). However, when the same polymers were added in turn to a $31 \mathrm{~nm}$ anionic silica sol ([silica $\left.]_{0}=0.05 \% \mathrm{w} / \mathrm{w}\right)$, then flocculation was observed in all cases (Table S2, Fig. S13†). In this case the length scales of the silica nanoparticles and the polymer coils are similar (tens of $\mathrm{nm}$ ). These control experiments serve to illustrate the difficulty of aggregating micrometer-sized particles using conventional water-soluble polymeric flocculants. This highlights the exceptional performance of the cross-linked cationic worms revealed in this study: the mean contour length of these highly anisotropic particles is comparable to the mean silica diameter, which accounts for their 'superflocculant' behavior.

\section{Conclusions}

In summary, chain extension of a binary mixture of $\mathrm{PEO}_{113}$ and PQDMA $_{125}$ macro-CTAs with HPMA using RAFT aqueous dispersion polymerization at $20 \% \mathrm{w} / \mathrm{w}$ solids can be used to prepare cationic diblock copolymer nano-objects. In particular, incorporation of $10 \mathrm{~mol}^{2} \mathrm{PQDMA}_{125}$ while targeting an appropriate degree of polymerization for the core-forming PHPMA block enables the formation of linear copolymer worms (zeta potential $=+35 \mathrm{mV}$ ) that remain highly cationic across a wide $\mathrm{pH}$ range. Core cross-linked cationic worms were readily prepared using epoxy-amine chemistry via statistical copolymerization of $20 \%$ mol GlyMA with HPMA, followed by addition of APTES. Extensive cross-linking occurs via reaction of the hydrolyzed pendent silanol groups with the secondary alcohol groups on the HPMA residues. Unlike the corresponding linear worms, these core cross-linked cationic worms can withstand the presence of either a cationic surfactant or methanol. Importantly, such cross-linked cationic worms are much more effective flocculants of highly anionic $1.0 \mu \mathrm{m}$ silica particles at $\mathrm{pH}$ 9. In contrast, the linear cationic worms are much less effective flocculants, because they break up to form a mixture of (mainly) non-ionic and cationic pseudo-spherical block copolymer nanoparticles. To benchmark the exceptional performance of the cross-linked cationic worms, a series of four high molecular weight commercial water-soluble polymers were also evaluated under the same conditions and found to be only weak flocculants for $1.0 \mu \mathrm{m}$ silica particles. Finally, preliminary experiments confirmed that these cross-linked cationic worms can also flocculate $4 \mu \mathrm{m}$ (and even $8 \mu \mathrm{m}$ ) anionic silica particles at $\mathrm{pH} 9$. 


\section{Acknowledgements}

EPSRC and Procter and Gamble (Brussels Technical Center, Belgium) are thanked for supporting a CASE PhD studentship for NJWP. SPA acknowledges an ERC Advanced Investigator grant (PISA 320372). The Oversea Study Program of Guangzhou Elite Project is thanked for sponsorship of a Ph.D. studentship for Y. N. Dr Svetomir Tzokov is thanked for supplying the carbon-coated TEM grids used in this study. Dr Matthew J. Derry is thanked for his comments on an early draft of this manuscript.

\section{Notes and references}

1 A. Swerin and L. Wågberg, Nord. Pulp Pap. Res. J., 1994, 9, 1825.

2 R. Nicu, E. Bobu and J. Desbrieres, Cellul. Chem. Technol., 2011, 45, 105-111.

3 M. S. Nasser and A. E. James, Sep. Purif. Technol., 2006, 52, 241-252.

4 S.-K. Kam and J. Gregory, Water Res., 2001, 35, 3557-3566. 5 B. Bolto and J. Gregory, Water Res., 2007, 41, 2301-2324.

6 M. Isik, A. M. Fernandes, K. Vijayakrishna, M. Paulis and D. Mecerreyes, Polym. Chem., 2016, 7, 1668-1674.

7 A. Bleier and E. D. Goddard, Colloids Surf., 1980, 1, 407-423. 8 D. Solberg and L. Wågberg, Colloids Surf., A, 2003, 219, 161172.

9 Y. Zhou, Y. Gan, E. J. Wanless, G. J. Jameson and G. V. Franks, Langmuir, 2008, 24, 10920-10928.

10 Y. Zhou and G. V. Franks, Langmuir, 2006, 22, 6775-6786.

11 M. Mende, S. Schwarz, G. Petzold and W. Jaeger, J. Appl. Polym. Sci., 2007, 103, 3776-3784.

12 C. Flood, T. Cosgrove, Y. Espidel, I. Howell and P. Revell, Langmuir, 2008, 24, 7323-7328.

13 S. Schwarz, K. Lunkwitz, B. Kessler, U. Spiegler, E. Killmann and W. Jaeger, Colloids Surf., A, 2000, 163, 17-27.

14 X. Wang, G. Guerin, H. Wang, Y. Wang, I. Manners and M. A. Winnik, Science, 2007, 317, 644-647.

15 Y.-Y. Won, H. T. Davis and F. S. Bates, Science, 1999, 283, 960-963.

16 H. Qiu, V. A. Du, M. A. Winnik and I. Manners, J. Am. Chem. Soc., 2013, 135, 17739-17742.

17 J. Massey, K. N. Power, I. Manners and M. A. Winnik, J. Am. Chem. Soc., 1998, 120, 9533-9540.

18 Y. Geng and D. E. Discher, J. Am. Chem. Soc., 2005, 127, 12780-12781.

19 Y.-Y. Won, K. Paso, H. T. Davis and F. S. Bates, J. Phys. Chem. $B, 2001,105,8302-8311$.

20 J. B. Gilroy, T. Gaedt, G. R. Whittell, L. Chabanne, J. M. Mitchels, R. M. Richardson, M. A. Winnik and I. Manners, Nat. Chem., 2010, 2, 566-570.

21 P. A. Rupar, L. Chabanne, M. A. Winnik and I. Manners, Science, 2012, 337, 559-562.

22 N. Petzetakis, A. P. Dove and R. K. O'Reilly, Chem. Sci., 2011, 2, 955-960.

23 Y. Geng, P. Dalhaimer, S. Cai, R. Tsai, M. Tewari, T. Minko and D. E. Discher, Nat. Nanotechnol., 2007, 2, 249-255.
24 S. Cai, K. Vijayan, D. Cheng, E. M. Lima and D. E. Discher, Pharm. Res., 2007, 24, 2099-2109.

25 A. H. Groschel, A. Walther, T. I. Lobling, F. H. Schacher, H. Schmalz and A. H. E. Muller, Nature, 2013, 503, 247-251. 26 Y. Kang, A. Pitto-Barry, A. Maitland and R. K. O'Reilly, Polym. Chem., 2015, 6, 4984-4992.

27 A. O. Moughton and R. K. O'Reilly, Chem. Commun., 2010, 46, 1091-1093.

28 E. T. Garrett, Y. Pei and A. B. Lowe, Polym. Chem., 2016, 7, 297-301.

29 Y. Pei, N. C. Dharsana and A. B. Lowe, Aust. J. Chem., 2015, 68, 939-945.

30 W. Zhang, F. D'Agosto, O. Boyron, J. Rieger and B. Charleux, Macromolecules, 2011, 44, 7584-7593.

31 J. Rieger, C. Grazon, B. Charleux, D. Alaimo and C. Jerome, J. Polym. Sci., Part A: Polym. Chem., 2009, 47, 2373-2390.

32 M. Dan, F. Huo, X. Xiao, Y. Su and W. Zhang, Macromolecules, 2014, 47, 1360-1370.

33 W.-J. Zhang, C.-Y. Hong and C.-Y. Pan, Macromolecules, 2014, 47, 1664-1671.

34 W. Zhao, G. Gody, S. Dong, P. B. Zetterlund and S. Perrier, Polym. Chem., 2014, 5, 6990-7003.

35 M. J. Derry, L. A. Fielding and S. P. Armes, Polym. Chem., 2015, 6, 3054-3062.

36 L. A. Fielding, M. J. Derry, V. Ladmiral, J. Rosselgong, A. M. Rodrigues, L. P. D. Ratcliffe, S. Sugihara and S. P. Armes, Chem. Sci., 2013, 4, 2081-2087.

37 W. Cai, W. Wan, C. Hong, C. Huang and C. Pan, Soft Matter, 2010, 6, 5554.

38 W. D. He, X. L. Sun, W. M. Wan and C. Y. Pan, Macromolecules, 2011, 44, 3358-3365.

39 S. Boisse, J. Rieger, K. Belal, A. Di-Cicco, P. Beaunier, M.-H. Li and B. Charleux, Chem. Commun., 2010, 46, 19501952.

40 X. Zhang, S. Boisse, W. Zhang, P. Beaunier, F. D'Agosto, J. Rieger and B. Charleux, Macromolecules, 2011, 44, 41494158.

41 S. Boisse, J. Rieger, G. Pembouong, P. Beaunier and B. Charleux, J. Polym. Sci., Part A: Polym. Chem., 2011, 49, 3346-3354.

42 W. Zhang, F. D'Agosto, O. Boyron, J. Rieger and B. Charleux, Macromolecules, 2012, 45, 4075-4084.

43 W. Zhang, F. D'Agosto, P.-Y. Dugas, J. Rieger and B. Charleux, Polymer, 2013, 54, 2011-2019.

44 M. Semsarilar, N. J. W. Penfold, E. R. Jones and S. P. Armes, Polym. Chem., 2015, 6, 1751-1757.

45 M. Williams, N. J. W. Penfold, J. R. Lovett, N. J. Warren, C. W. I. Douglas, N. Doroshenko, P. Verstraete, J. Smets and S. P. Armes, Polym. Chem., 2016, 7, 3864-3873.

46 C. J. Ferguson, R. J. Hughes, B. T. T. Pham, B. S. Hawkett, R. G. Gilbert, A. K. Serelis and C. H. Such, Macromolecules, 2002, 35, 9243-9245.

47 V. J. Cunningham, A. M. Alswieleh, K. L. Thompson, M. Williams, G. J. Leggett, S. P. Armes and O. M. Musa, Macromolecules, 2014, 47, 5613-5623.

48 N. J. Warren, O. O. Mykhaylyk, D. Mahmood, A. J. Ryan and S. P. Armes, J. Am. Chem. Soc., 2014, 136, 1023-1033. 
49 Q. Zhang and S. Zhu, ACS Macro Lett., 2015, 4, 755-758.

50 B. Zhang, X. Yan, P. Alcouffe, A. Charlot, E. Fleury and J. Bernard, ACS Macro Lett., 2015, 4, 1008-1011.

51 M. J. Derry, L. A. Fielding and S. P. Armes, Prog. Polym. Sci., 2016, 52, 1-18.

52 J. Lesage de la Haye, X. Zhang, I. Chaduc, F. Brunel, M. Lansalot and F. D'Agosto, Angew. Chem., Int. Ed., 2016, 55, 3739-3743.

53 T. Boursier, S. Georges, M. Mosquet, D. Rinaldi and F. D'Agosto, Polym. Chem., 2016, 7, 917-925.

54 N. J. Warren and S. P. Armes, J. Am. Chem. Soc., 2014, 136, 10174-10185.

55 C. J. Mable, N. J. Warren, K. L. Thompson, O. O. Mykhaylyk and S. P. Armes, Chem. Sci., 2015, 6, 6179-6188.

56 P. Yang, L. P. D. Ratcliffe and S. P. Armes, Macromolecules, 2013, 46, 8545-8556.

57 A. Blanazs, R. Verber, O. O. Mykhaylyk, A. J. Ryan, J. Z. Heath, C. W. Douglas and S. P. Armes, J. Am. Chem. Soc., 2012, 134, 9741-9748.

58 R. Verber, A. Blanazs and S. P. Armes, Soft Matter, 2012, 8, 9915-9922.

59 K. A. Simon, N. J. Warren, B. Mosadegh, M. R. Mohammady, G. M. Whitesides and S. P. Armes, Biomacromolecules, 2015, 16, 3952-3958.

60 K. L. Thompson, C. J. Mable, A. Cockram, N. J. Warren, V. J. Cunningham, E. R. Jones, R. Verber and S. P. Armes, Soft Matter, 2014, 10, 8615-8626.

61 D. E. Mitchell, J. R. Lovett, S. P. Armes and M. I. Gibson, Angew. Chem., Int. Ed., 2016, 55, 2801-2804.

62 N. J. W. Penfold, J. R. Lovett, N. J. Warren, P. Verstraete, J. Smets and S. P. Armes, Polym. Chem., 2016, 7, 79-88.

63 J. R. Lovett, N. J. Warren, L. P. D. Ratcliffe, M. K. Kocik and S. P. Armes, Angew. Chem., Int. Ed., 2015, 54, 1279-1283.

64 L. A. Fielding, J. A. Lane, M. J. Derry, O. O. Mykhaylyk and S. P. Armes, J. Am. Chem. Soc., 2014, 136, 5790-5798.

65 Y. Pei, O. R. Sugita, L. Thurairajah and A. B. Lowe, RSC Adv., 2015, 5, 17636-17646.

66 Y. Pei, L. Thurairajah, O. R. Sugita and A. B. Lowe, Macromolecules, 2015, 48, 236-244.

67 N. Penfold, J. R. Lovett, P. Verstraete, J. Smets and S. P. Armes, Polym. Chem., 2016, 7, 79, DOI: 10.1039/ C5PY01510C, in the press.

68 V. Bütün, A. B. Lowe, N. C. Billingham and S. P. Armes, J. Am. Chem. Soc., 1999, 121, 4288-4289.
69 R. K. O'Reilly, C. J. Hawker and K. L. Wooley, Chem. Soc. Rev., 2006, 35, 1068-1083.

70 A. Guo, G. Liu and J. Tao, Macromolecules, 1996, 29, 24872493.

71 P. Chambon, A. Blanazs, G. Battaglia and S. P. Armes, Langmuir, 2012, 28, 1196-1205.

72 M. J. Joralemon, R. K. O'Reilly, C. J. Hawker and K. L. Wooley, J. Am. Chem. Soc., 2005, 127, 16892-16899.

73 Q. Zhang, E. E. Remsen and K. L. Wooley, J. Am. Chem. Soc., 2000, 122, 3642-3651.

74 S. Liu, J. V. M. Weaver, Y. Tang, N. C. Billingham, S. P. Armes and K. Tribe, Macromolecules, 2002, 35, 6121-6131.

75 S. Sugihara, S. P. Armes, A. Blanazs and A. L. Lewis, Soft Matter, 2011, 7, 10787-10793.

76 J. R. Lovett, L. P. D. Ratcliffe, N. J. Warren, S. P. Armes and B. R. Saunders, Macromolecules, 2016, 49, 2928-2941.

77 A. E. Smith, X. Xu, T. U. Abell, S. E. Kirkland, R. M. Hensarling and C. L. McCormick, Macromolecules, 2009, 42, 2958-2964.

78 G. Liu, Q. Qiu, W. Shen and Z. An, Macromolecules, 2011, 44, 5237-5245.

79 M. Semsarilar, V. Ladmiral, A. Blanazs and S. P. Armes, Langmuir, 2012, 28, 914-922.

80 M. Semsarilar, V. Ladmiral, A. Blanazs and S. P. Armes, Langmuir, 2013, 29, 7416-7424.

81 M. Williams, N. J. W. Penfold and S. P. Armes, Polym. Chem., 2016, 7, 384-393.

82 A. P. Lopez-Oliva, N. J. Warren, A. Rajkumar, O. O. Mykhaylyk, M. J. Derry, K. E. B. Doncom, M. J. Rymaruk and S. P. Armes, Macromolecules, 2015, 48, 3547-3555.

83 S. A. Buckingham, C. J. Garvey and G. G. Warr, J. Phys. Chem., 1993, 97, 10236-10244.

84 P. Ekwall, L. Mandell and P. Solyom, J. Colloid Interface Sci., 1971, 35, 519-528.

85 N. L. McFarlane, N. J. Wagner, E. W. Kaler and M. L. Lynch, Langmuir, 2010, 26, 13823-13830.

86 F. Lafuma, K. Wong and B. Cabane, J. Colloid Interface Sci., 1991, 143, 9-21.

87 F. Mabire, R. Audebert and C. Quivoron, J. Colloid Interface Sci., 1984, 97, 120-136.

88 A. Blanazs, J. Madsen, G. Battaglia, A. J. Ryan and S. P. Armes, J. Am. Chem. Soc., 2011, 133, 16581-16587. 